\title{
Editorial
}

\section{Cuidados de la Salud Centrado en la Persona}

\author{
Person Centered Health Care
}

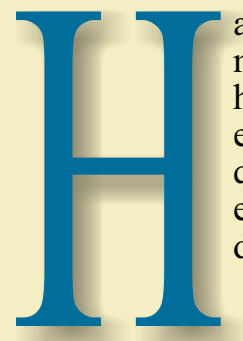

acer salud pública hoy, exige muchos cambios en la visión que hemos tenido sobre los enfoques en la salud. Estos hacen necesario que tengamos una visión y un enfoque transformado para actuar diferente.

Amelita es de un pueblo remoto de Loreto, madre de una pequeña niña. Se llega en "pequepeque" por el río Amazonas. Vivió con un tumor en el vientre (pensó al inicio que estaba embarazada), creció tanto que ya no podía a caminar, lo cual la obligaba a estar acostada en su hamaca.

Con apoyo de la sociedad civil se logró trasladarla a Lima en un avión de la Fuerza Aérea Peruana (FAP). Luego de arribar, fue atendida en el Instituto Nacional de Enfermedades Neoplásicas (INEN), donde se le diagnosticó un tumor retroperitoneal, siendo hospitalizada y sometida a una exitosa cirugía. El diagnóstico: Tumor Retroperitoneal. La información compartitida con la paciente logró involucrarla en el acto previo y posterior al tratamiento, permitiendo su progreso satisfactorio. Días después regresó a su lugar de origen para reincorporarse con su familia, $\mathrm{y}$ actualmente se encuentra en buen estado de salud.

Durante muchos años nos hemos basado en números de atenciones, resultados de supervivencia, tasas de recurrencia de la enfermedad. Grandes números como indicadores de gestión, lo cual nos permitía tener una información panorámica de las enfermedades; no obstante, esto nos llevó a favorecer la centralización de la atención, traducida en los indicadores de las instituciones prestadoras de servicios de salud. Desde 1986, con la famosa Carta de Ottawa, se retoma una visión que por cientos de años se había puesto en práctica por casos particulares, como el de Amelita, en la que se establecen principios básicos en donde el sistema sanitario no es el centro sino el mediador, donde los modelos giraban alrededor del campo de la salud; sin embargo, esa visión en once años cambia, plasmándose en la lógica de la promoción de la salud.

Dicho documento presentó una visión para abordar un cambio en el sistema de salud, estableciendo entre uno de sus pilares: "el reconocimiento de que los individuos constituyen la principal fuente de salud; a apoyarlos y capacitarlos a todos los niveles para que ellos y sus familias y amigos se mantengan en buen estado de salud". De esa forma, son los sistemas que deben girar alrededor del paciente, centrándolo durante su atención y recuperación; desde entonces, este pilar de conocimiento se viene trabajando para ser incorporado como parte de las políticas públicas, y ha sido motivo de debate en el mundo, llegando a clarificar el importante rol que el paciente debe jugar, centrado en los sistemas modernos de salud. Por lo tanto, en ese ánimo de brindar una atención integral, se debe considerar la información y la forma en cómo se comunica, generando una relación de confianza, bienestar, al trasladarla oportuna y eficazmente hacia el paciente.

En ese sentido, considero valioso el presente artículo, pues permite conocer herramientas que, de ser incorporadas por los profesionales médicos quirúrgicos y equipo de trabajo, resultarán en un enfoque más integral y humano.

Dr. Eduardo Payet-Meza Jefe Institucional del INEN.

Citar como: Payet-Meza E. Cuidados de la Salud Centrado en la Persona.

Diagnóstico (Lima). 2021;60(1):3.

DOI: 10.33734 /diagnostico.v60i1.265 